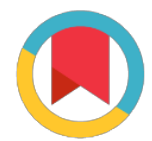

Check for updates
*For correspondence:

bhthuy@hcmiu.edu.vn

Competing interests: The authors declare that no competing interests exist.

Received: 2017-07-15

Accepted: 2017-08-05

Published: 2017-09-05

Copyright The Author(s) 2017. This article is published with open access by BioMedPress (BMP).

This article is distributed under the terms of the Creative Commons Attribution License (CC-BY 4.0) which permits any use, distribution, and reproduction in any medium, provided the original author(s) and the source are credited.

\section{Effect of caffeine supplementation during in vitro maturation on development of parthenogenetic embryos derived from aging oocytes}

\author{
Nguyen Thi Thuy Van ${ }^{1,2}$, Doanh Duc Nghia ${ }^{1}$, Nguyen Van Thuan ${ }^{1}$, Hong- \\ Thuy Bui ${ }^{1}$ \\ ${ }^{1}$ Cell Reprogramming Lab, Department of Biotechnology, International University-National \\ University, Vietnam \\ ${ }^{2}$ Institute of Tropical Biology, Vietnam Academy of Science and Technology, Vietnam
}

\begin{abstract}
"Oocyte aging" refers to degradation of oocytes which is considered as consequence of long time nuclear transfer manipulation which leads to the reduced success rate of somatic nuclear transfer (SCNT). Caffeine, which has ability of maintenance of the maturation-promoting factor (MPF) from oocyte metaphase, is considered as an improvement factor of oocyte quality. However, the influence of caffeine in aged oocytes in which duration of oocyte development is still unknown. In this study, the supplementation of caffeine during in vitro maturation of porcine embryos (from metaphase I to metaphase II) was examined on the parthenogenesis models and evaluated its effect in aged oocyte quality. After reaching metaphase I stage (27 hours) of in vitro maturation (IVM), oocytes were continuously cultured with or without $5 \mathrm{mM}$ caffeine until metaphase II ( 42 hours), then induced aging in basic medium without hormone for 6 hours before parthenogenesis activation. Results indicated that the supplementation of caffeine at metaphase I to metaphase II during in vitro maturation had significantly improved the development of embryo to four-cell, eight-cell and importantly blastocyst stage. There was noticeably significant improvement in rate and quality of blastocyst of aging oocytes treated with caffeine compared to non-treated group ( $39.1 \%$ and $10.3 \%$, respectively). Furthermore, caffeine treatment can reduce the fragmentation of aging oocyte. Hence, the interpretation of caffeine supplementation during metaphase I to metaphase II could improve the quality of embryo development and quality of blastocysts developed from aging oocytes (6 hours).
\end{abstract}

\section{Keywords}

caffeine, in vitro maturation, aging oocyte, porcine oocyte, electro-activation, parthenogenesis Funding

References 